Wiaczesław Nowikow

Uniwersytet Łódzki

nowikow_2000@yahoo.com.mx

\title{
La organización de los sistemas temporales del español y del polaco: análisis contrastivo de los tiempos verbales ${ }^{1}$
}

\begin{abstract}
:
The Temporal Organization of the Spanish and Polish Language Systems: Contrastive Analysis of Tenses

The paper discusses differences between Polish and Spanish tense systems. It takes into account parameters such as the quantity and the systemic organization of time (temporary relationship and reference), the existence of the compound tenses subsystem, temporal mono- and biaxiality; dislocation (displacement) of tenses. The comparison is performed by considering the typological differences between Spanish and Polish languages.
\end{abstract}

Keywords: tenses, Spanish vs Polish, contrastive Analysis, typology

${ }^{1}$ Este estudio es una versión modificada y ampliada del artículo "Sobre las diferencias entre el sistema verbal del español y el del polaco: característica temporal", publicado en la revista Paralelo 50, n. 2 (2005), pp. 78-83. La publicacion del presente trabajo ha sido posible gracias a la amabilidad del Sr. Félix Herrero Castrillo, editor de la revista Paralelo 50. 


\section{Streszczenie:}

Organizacja systemów czasowych w języku hiszpańskim i polskim: kontrastywna analiza czasów gramatycznych

W artykule przeanalizowano różnice między systemami czasów w językach hiszpańskim i polskim. Uwzględniono takie parametry, jak: ilość i organizacja systemowa czasów (relacje i referencje temporalne), istnienie subsystemu czasów złożonych, jedno- i dwuosiowość temporalna, dyslokacja (przesunięcie) czasów. Analizy porównawczej dokonano przy uwzględnieniu różnic typologicznych między językami hiszpańskim a polskim.

Słowa kluczowe: czasy gramatyczne, język hiszpański vs język polski, analiza kontrastywna, różnice strukturalne, systemowe i typologiczne

\section{Planteamiento tipológico}

Como señalan algunos lingüistas [véase, a este respecto, p.ej., Pátrovics, 2000], desde la perspectiva tipológica hay dos tipos de lenguas:

1) Unas, a las que pertenecen idiomas eslavos del Norte tales como el polaco, el ruso, el checo, pero también el gótico, el Althochdeutsch o el sorabio coloquial, no poseen en sus sistemas gramaticales el artículo y disponen de pocos tiempos verbales. Los idiomas señalados supra cuentan, en cambio, con las categorías de aspecto y de caso morfologizadas mediante significantes específicos. Son las llamadas lenguas "aspecto + caso". Es verdad que en polaco y en ruso los pronombres demostrativos a veces son capaces de cumplir las funciones propias del artículo, por ejemplo, la anafórica. Sin embargo, las dos lenguas eslavas no poseen formas específicas del artículo, con lo cual, a diferencia de lo que ocurre en castellano, el contenido genérico (categorial) no tiene en ellas expresión morfológica (p.ej., El león es el rey de la selva vs øLew jest królem selwy) [cfr. Nowikow, 2012a].

2) Otras, tales como, p.ej., el búlgaro o el Mittelhochdeutsch, poseen tanto el artículo como el sistema temporal bien desarrollado. No obstante, estas últimas lenguas, a diferencia de los idiomas del primer 
tipo, no cuentan, grosso modo, con el aspecto (o lo tienen "menos desarrollado") ni tampoco con el sistema casual. El castellano, por ejemplo, dispone de las formas pronominales de $3^{\mathrm{a}}$. persona específicas para los complementos directo e indirecto (le, lo, la, etc.) que representan los restos del antiguo sistema casual latino. No obstante, los elementos nominales (sustantivo, adjetivo) del español actual carecen de la categoría de caso con expresión morfológica [véase, a este respecto, p.ej., Nowikow, 2012b]. Se trata de las llamadas lenguas "artículo + tiempo".

De modo que a nivel tipológico y desde el punto de vista de las preferencias en la marcación morfológica, existen dos grupos de lenguas:

- lenguas AC: aspecto + caso y

- lenguas ArtT: artículo + tiempo.

No cabe duda de que el español pertenece al segundo tipo (ArtT) mientras que el polaco al primero (AC) [cfr., a este respecto, también Nowikow, 2013a].

Ahora bien, en el presente estudio vamos a centrar nuestra atención en las diferencias existentes entre el sistema temporal (tiempos verbales) del castellano y del polaco modernos.

\section{Los tiempos en la descripción gramatical contrastiva: diferencias vs semejanzas}

Nos van a interesar en primer lugar las diferencias y no las semejanzas, puesto que, en nuestra opinión, son las primeras las que al destacar las particularidades formales y funcionales, caracterizan la idiosincrasia de los sistemas verbales en cuestión. Por otra parte, en la enseñanza a menudo se hace hincapié en las semejanzas partiendo de la tesis sobre la utilidad de estas últimas en el aprendizaje. Sin descartar la necesidad de buscar un tertium comparationis o los llamados denominadores comunes, cabe señalar que en el caso de sistemas 
temporales tan distintos como la del castellano y la del polaco, las semejanzas se dan sobre todo a nivel ontológico o el de designación siendo las coincidencias propiamente lingüísticas muy escasas. De modo que creemos conveniente destacar en primer lugar las diferencias para que las semejanzas no desempeñen el papel de los llamados falsos amigos, fenómeno muy bien conocido en el aprendizaje del léxico. Pasemos ahora, sin más preámbulos, a un breve análisis contrastivo de los tiempos gramaticales del castellano y del polaco señalando a la vez que las observaciones presentadas a continuación son, grosso modo, válidas para lenguas eslavas del Norte tales como el checo, el eslovaco o el ruso.

\section{Características cuantitativas y la repartición interna}

Los tiempos verbales del español y del polaco se presentan de la siguiente manera (utilizamos la nomenclatura de los tiempos propuesta por Bello [1847/1984] y empleada por Rojo y Veiga [1999] que nos parece más adecuada para la descripción del sistema temporal castellano):

\begin{tabular}{llll}
\hline \multicolumn{2}{c}{ SUBJUNTIVO } & \multicolumn{2}{c}{ TRYB WARUNKOWY } \\
\hline \multicolumn{1}{c}{ Tiempo } & \multicolumn{1}{c}{ Español } & \multicolumn{2}{c}{ Polaco } \\
\hline Pres. & escriba & Asp. Imperf. & Asp. Perf. \\
Co-pret. & escribiera, -se & pisalby & napisalby \\
Ante-pres. & haya escrito & & \\
Ante-co-pr. & hubiera,-se escrito & & \\
\hline
\end{tabular}




\begin{tabular}{|c|c|c|c|c|}
\hline \multicolumn{3}{|c|}{ INDICATIVO } & \multirow{2}{*}{\multicolumn{2}{|c|}{$\begin{array}{c}\text { TRYB OZNAJMUJĄCY } \\
\text { Polaco }\end{array}$}} \\
\hline \multirow[t]{2}{*}{ Tiempo } & \multirow[t]{2}{*}{ Español } & \multirow[t]{2}{*}{ Tiempo } & & \\
\hline & & & Asp. Imperf. & Asp. Perf. \\
\hline Presente & escribe & Presente & pisze & --- \\
\hline Pretérito & escribió & & & \\
\hline Co-pret. & escribia & Pasado & pisat & napisat \\
\hline Ante-pres. & ha escrito & & & \\
\hline Ante-pret. & había ecrito & & & \\
\hline Futuro & escribirá & & & \\
\hline Ante-fut. & $\begin{array}{l}\text { habrá } \\
\text { escrito }\end{array}$ & Futuro & będzie pisat & napisze \\
\hline Pos-pret. & escribiría & & & \\
\hline Ante-pos-pr. & $\begin{array}{l}\text { habria } \\
\text { escrito }\end{array}$ & & & \\
\hline
\end{tabular}

Como se ve, se dan diferencias considerables tanto a nivel cuantitativo como con respecto a la repartición interna de los tiempos verbales del castellano y del polaco. En español el modo indicativo incluye 9 tiempos con expresión morfológica, mientras que en polaco el "tryb oznajmujący" (literalmente "modo declarativo") cuenta sólo con 3 tiempos que poseen sus propios significantes. Por otro lado, el modo subjuntivo (pol. "tryb łączący") castellano dispone de 6 formas temporales (incluidas en éstas los alomorfos en $-s e$ y en $-r a$ ). En cambio, su homólogo parcial (¡no hay equivalencias funcional y distribucional completas!) el "tryb warunkowy (przypuszczający)" (literalmente "modo condicional o hipotético") polaco no posee más que un exponente temporal propio.

Cabe señalar que de hecho el polaco cuenta con 7 formas gramaticales (véase el cuadro supra). No obstante, esto se debe a la morfologización de la categoría de aspecto dentro de la cual se distinguen tres formas imperfectivas (pisze, pisat, będzie pisat, pisałby) y tres perfectivas (napisat, napisze, napisatby). Desde el punto de vista de la expresión de las relaciones temporales las parejas pisat / napisat, 
będzie pisat / napisze, pisatby / napisatby tienen carácter alomórfico, es decir, son portadores del mismo valor temporal expresado mediante diferentes significantes.

No hemos tomado en consideración los tiempos totalmente periféricos, matizados de sabor un tanto arcaico y de uso diastrática, diatópica y diafásicamente muy reducido. Nos referimos al llamado pretérito anterior (hubo cantado) y al futuro de subjuntivo (cantare) castellanos, así como al pluscuamperfecto de los modos indicativo y condicional polacos (véase infra).

En resumen, el sistema español cuenta con 13 subcategorías (tiempos) repartidos entre dos modos (indicativo: 9; subjuntivo: 4) mientras que el polaco dispone sólo de 4 paradigmas (indicativo: 3; modo condicional o hipotético: 1). Esta diferencia cuantitativa demuestra el abismo morfológico y paradigmático que separa las dos lenguas. Sin embargo, los morfemas representados por los morfos son unidades significativas, lo que condiciona importantes particularidades funcionales de los componentes de los sistemas verbales del castellano y del polaco tanto con relación al funcionamiento de cada uno de los tiempos como respecto a la organización global de estos últimos. Consideremos a continuación algunas de las características diferenciadoras más relevantes.

\section{El desdoblamiento temporal del castellano}

Al caracterizar el sistema temporal del castellano se recurre a menudo a conceptos tales como 'concordancia / correlación temporal' o a las dicotomías 'plano presente / plano pasado', 'mundo comentado / mundo narrado', etc. [cfr., a este respecto, Hernández Alonso, 1986: 318-322], p.ej.,

(1) Me dice que están muy contentos de las últimas vacaciones.

(2) Me dijo que estaban muy contentos de las últimas vacaciones. 
Si descartamos las particularidades diatópicas (en el Norte de la Península y en varias zonas de Hispanoamérica dijo reemplaza con frecuencia a ha dicho) y las actualizaciones discursivo-informativas que se dan, p.ej., en el lenguaje de la prensa (El presidente anunció que mañana secelebrará la reunión...) resulta evidente que en los ejemplos (1) y (2) se trata de dos orientaciones temporales distintas: la primera, marcada por dice, nos ubica en el propio momento de la enunciación (habla, elocución); la segunda, denotada por dijo, nos remite a un punto anterior al momento de habla. En otros términos, hay dos posibilidades con respecto a la orientación temporal del enunciado:

- referencia primaria o el origen [ej. (1)] y

- referencia secundaria, es decir, anterior a la primera [ej. (2)].

Cabe subrayar que la llamada referencia primaria o el origen [para el concepto de origen véase Rojo, 1974 y Rojo, Veiga, 1999] no tiene que coincidir necesariamente con el momento de la enunciación, identificado éste con un instante de índole físico-biológica. El origen es el momento escogido por el hablante como la referencia temporal más importante (¡de ahí su carácter primario!) a partir de la cual se establecen las relaciones temporales de los enunciados formulados y dirigidos al interlocutor del emisor del mensaje. La situación prototípica es, desde luego, la clásica conversación entre dos o más personas. Y es en esta última donde el origen suele coincidir con el momento de habla, $c f r$.

(3) 'Pues te digo que me encanta el metro!

frente a

(4) Pues te dije que me encantaba el metro, pero ahora no sé qué decir...

No obstante, no pasa lo mismo cuando al escribir una carta, contamos sobre nuestros planes futuros [cfr. Rojo, Veiga, 1999: 2889-2890]:

(5) Por fin puedo confirmarte quela semana que viene iré a Austria para participar en el congreso. 
El contacto entre el remitente y el destinatario se establece en el momento de la lectura de la carta por el receptor (es como si los dos estuviesen hablando). Mientras tanto es posible que el autor del mensaje ya haya ido a Austria, haya participado en el congreso e incluso haya regresado a casa. No obstante, en castellano el remitente escoge como el momento más importante el de escribir la carta y no el de la lectura por parte del destinatario. Este primer momento es precisamente la referencia temporal primaria o el origen. De ahí que para la simultaneidad y para la posterioridad se empleen el presente y el futuro de indicativo ( $\mathrm{y}$ no el copretérito y el pospretérito!), respectivamente.

En resumen, el sistema de los tiempos gramaticales del castellano es biaxial, es decir, se conforma en torno a dos ejes temporales cuyos centros son 1) la referencia temporal primaria (el origen) y 2) un punto anterior a ésta. Este hecho condiciona el empleo de determinados tiempos en determinadas combinaciones y distribuciones de índole temporal (véase los ejemplos 1-4).

A diferencia del español, en polaco, el empleo de las formas de pasado en los enunciados equivalentes a los ejemplos (2) y (4) no es más que opcional, siendo el presente también posible:

(6) Powiedziat mi, że sa (pres.) / byli (pas.) zadowoleni z ostatnich wakacji [ale teraz juz nie wie!].

(7) Powiedziałem Ci, że jestem (pres.) / bytem (pas.) zachwycony metrem [ale teraz nie wiem, co powiedzieć!].

De modo que el sistema de los tiempos gramaticales del polaco es monoaxial [ $c f r$. a este respecto, también Perlin, 1996], lo que quiere decir que los equivalentes polacos de dice y dijo españoles no exigen formas temporales específicas especializadas en la expresión de relaciones de anterioridad, simultaneidad o posterioridad respecto a un mówi o mówit/powiedziat. Sería difícil hacerlo al disponer el modo indicativo polaco solo de 3 tiempos: uno para la expresión de anterioridad y otros dos para las relaciones de simultaneidad y de posterioridad. En cambio, en español las relaciones temporales de anterioridad las establecen 5 formas (canté, cantaba, he cantado, habia cantado, 
habría cantado), las de simultaneidad las expresan 2 tiempos (canta, cantaba) y las de posterioridad también 2 (cantará, cantaría).

Cabe señalar que la biaxialidad del castellano está en una relación estrecha con otra característica importante de los tiempos españoles. Nos referimos a la distinción entre:

- los tiempos con relación fija y directa con la referencia primaria $\mathrm{y}$

- los tiempos sin relación fija y directa con la referencia primaria.

Por su parte, dicha distinción se ve relacionada con la duplicidad vectorial de los tiempos verbales del castellano actual [véase también Nowikow, 2013b].

\section{La duplicidad vectorial de los tiempos españoles}

En el estudio citado de Rojo y Veiga [1999: 2884] se encuentra un cuadro que presenta la organización y los valores gramaticales de todos los tiempos de indicativo. En otras palabras, esta pequeña tabla engloba todo el sistema temporal del español:

\begin{tabular}{|llll|}
\hline \multicolumn{4}{|c|}{ Punto de referencia Relación temporal primaria $-\mathbf{V o V}+\mathbf{V}$} \\
\hline $\mathrm{O}$ & canté & canto & cantaré \\
\hline$(\mathrm{O}-\mathrm{V})$ & había cantado & cantaba & cantaría \\
\hline$(\mathrm{OoV})$ & he cantado & & \\
\hline$(\mathrm{O}+\mathrm{V})$ & habré cantado & & \\
\hline$((\mathrm{O}-\mathrm{V})+\mathrm{V})$ & habría cantado & & \\
\hline
\end{tabular}

Los símbolos utilizados por los autores se reparten en dos grupos:

1) referencias temporales entre las cuales destacan:

$\mathrm{O}-$ el origen o la referencia primaria (básicamente, aunque no siempre, se trata del momento de la enunciación, véase supra); $\mathrm{O}-\mathrm{V}$ - un momento anterior al origen o la referencia secundaria.

2) relaciones temporales: 
-V - relación o vector de anterioridad;

$\mathrm{oV}$ - relación o vector de simultaneidad;

$+\mathrm{V}$ - relación o vector de posterioridad.

Además, es necesario distinguir entre dos tipos de relaciones o vectores temporales. Según Veiga [2008: 71], en el valor gramatical de los tiempos verbales hay vectores de dos tipos: uno, primario y otro, originario. El primero se refiere [Veiga, 2008: 48, n. 42] "a la perspectiva temporal que todo hecho verbalmente expresado recibe directamente desde el punto de referencia temporal más próximo, que viene a ser el centro deíctico de referencias temporales en el caso de orientaciones como las de pretérito, presente o futuro y una referencia anterior a dicho centro deíctico en el de las de ante-pretérito, co-pretérito o pos-pretérito. Cfr. El concepto de relación temporal primaria en Rojo [1974: §4.1.]". A diferencia de la relación primaria, el vector originario se refiere a la orientación interna de la referencia temporaldentro de la cual se establecen relaciones de anterioridad $(\mathrm{O}-\mathrm{V})$, simultaneidad $(\mathrm{OoV})$ o posterioridad $(\mathrm{O}+\mathrm{V})$ respecto al origen. En resumen, el vector originario afecta a la característica temporal de la referencia y no a la relación que mantiene con aquella primera el tiempo verbal.

Al analizar el cuadro, llaman la atención las siguientes características del sistema temporal castellano:

1) la mayoría de los tiempos mantiene relación temporal o directamente con el origen $\mathrm{O}$ (3: pretérito canté, presente canto, futuro cantaré) o con un punto anterior a este O-V (3: antepretérito había cantado, copretérito cantaba, pospretérito cantaría);

2) del total de 9 tiempos 5 expresan relación temporal primaria de anterioridad: canté, habia cantado, he cantado, habré cantado, habría cantado; señalemos que en 4 casos se trata de las formas compuestas.

Ahora bien, limitándonos a los tiempos simples de indicativo cabe subrayar que con respecto a la relación originaria los hay de dos tipos. Al primero pertenecen presente (escribe), pretérito (escribió) y futuro (escribirá) mientras que el segundo incluye copretérito (escribía) y pospretérito (escribiría). Los primeros siempre expresan simulta- 
neidad (presente), anterioridad (pretérito) y posterioridad (futuro) con respecto a la referencia primaria (origen), mientras que los segundos siempre denotan simultaneidad (copretérito) y posterioridad (pospretérito) medidas desde un punto anterior a la referencia primaria:

(8) Escribo una carta (en este momento).

(9) Ayer escribí una carta.

(10) Mañana escribiré una carta.

pero:

(11) * Ayer escribiré una carta.

(12) *Mañana escribí una carta.

En cambio enunciados tales como

(13) Me dijo que escribía / escribiría una carta

suponen la posibilidad de tres orientaciones temporales con el origen, es decir:

- $\quad$ ya la escribí\}

- $\quad\{$ la estoy escribiendo $\}$

- $\quad$ la escribiré más tarde\}

Las únicas relaciones fijas que mantienen escribia y escribiría son las de simultaneidad y posterioridad respecto al punto anterior a la referencia primaria marcado por dijo.

Es obvio que el polaco no posee la distinción en cuestión, puesto que cualquier tiempo de esta última lengua puede establecer la orientación con respecto a las dos referencias temporales comentadas $s u$ pra. El hecho no es nada extraño al poseer el polaco sólo un tiempo de pasado (pisat/napisal) y uno de futuro (będzie pisat / napisze).

Todo lo que hemos señalado hasta el momento sobre los tiempos castellanos se refiere al valor gramatical básico que determina la posición que ocupa cada uno de los tiempos dentro del sistema verbal. No obstante, no hay reglas sin excepción: al lado del valor de sistema (recto) existen valores "metafóricos" que se dan a consecuencia de dislocación [el término utilizado por Rojo, 1974 y por Rojo, Veiga, 1999] o desplazamiento temporales. Se trata de una propiedad muy 
importante del funcionamiento de los tiempos gramaticales en el español actual.

\section{La dislocación o el desplazamiento temporales}

Como hemos advertido supra, el valor básico del futuro escribirá consiste en la expresión de posterioridad respecto a la referencia temporal primaria:

(14) Te prometo que escribiré la carta esta tarde.

Sin embargo, como es sabido, el futuro se utiliza también en enunciados tales como:

(15) ¿Cuántos años tiene Juan?

(16) Tendrá veinte.

Es evidente que en este último caso la forma del futuro no denota posterioridad sino simultaneidad con referencia al origen. A consecuencia de este desplazamiento temporal, el futuro adquiere el rasgo modal 'incertidumbre' o 'probabilidad' (Juan probablemente / a lo mejor tiene veinte años). Es el primer tipo de dislocación temporal.

Los desplazamientos temporales del segundo tipo se dan con los tiempos cuyo valor básico incluye la expresión de una relación de anterioridad. Al producirse la dislocación, esta última se ve sustituida por la de simultaneidad. Por ejemplo, en

(17) - Me voy a Madrid.

- Yo también me iba a Madrid.

la forma iba denota simultaneidad, pero no con respecto a un punto anterior al origen sino con referencia directa a este último. Como resultado, aparece el contenido modal 'no-realidad': el hablante no va a Madrid. 
De modo que en ambos casos el mecanismo es el mismo: la sustitución del valor temporal básico (recto) por el valor temporal dislocado (metafórico) provoca la aparición de nuevos valores modales epistémicos: el de incertidumbre / probabilidad o el de no-realidad. El primero de estos valores modales se ve originado por el cambio temporal de "retroceso": el futuro en vez de expresar posterioridad denota simultaneidad. El segundo valor modal surge como resultado del desplazamiento de "propulsión": el copretérito deja de establecer relaciones con un punto anterior a la referencia primaria y empieza a hacerlo directamente respecto a esta última.

En polaco la dislocación temporal existe como fenómeno gramatical restringido y marginal, pero no como principio general. Los desplazamientos temporales son posibles en algunos casos con ciertos predicados, p.ej.:

(18) - Ile lat ma Jan? (esp. ¿Cuántos años tiene Juan?)

- Będzie mial [ze / około] 20. (esp. Tendrá [aproximadamente] 20)

(19) Chciatem $[=$ chce $]$ z toba poważnie porozmawiać. (esp. Quería $[=$ quiero $]$ hablar contigo seriamente).

Sin embargo, se trata de empleos aislados sin consecuencias obligatorias para el valor modal (éste cambia en el ejemplo (18) pero no en el (19) ) que se dan, a veces, con el apoyo de algunos elementos léxicos (ze / około; esp. aproximadamente, a eso de). Además, los usos en cuestión a menudo se ven matizados diafásicamente. Así, el ejemplo (18) es un coloquialismo.

En español, en cambio, se trata de un principio general y fundamental de la organización del sistema temporal. Al mismo tiempo dicho principio funciona con frecuencia y eficacia como uno de los mecanismos de modalización del enunciado. 


\section{El subsistema de los tiempos compuestos}

Sin entrar en los detalles, quisiéramos llamar la atención sobre la existencia en el sistema temporal del español actual de un desarrollado subsistema de los tiempos compuestos: haber + infinitivo [cfr., a este respecto, Cartagena, 1999; Veiga, 1991]. Como hemos señalado (véase supra), entre 9 tiempos del modo indicativo 4 son compuestos. Esta creación románica basada en la desemantización del verbo auxiliar y en la gramaticalización paulatina de la construcción, desempeña un papel importante en el establecimiento de las relaciones de anterioridad, siempre con respecto al tiempo de su verbo auxiliar: ha escrito anterior a escribe, habrá escrito anterior a escribirá, etc. De hecho casi todos los tiempos ( $₫ 4$ de 5!) que establecen la relación temporal primaria de anterioridad son compuestos. Podríamos decir que en el español actual la anterioridad temporal primaria se expresa casi exclusivamente por los tiempos compuestos. Este es su valor gramatical de sistema. Las diferencias entre los tiempos compuestos se refieren al vector originario (véase la última tabla presentada supra).

El polaco actual no posee tiempos compuestos en su sistema temporal. Aunque en las grámaticas todavía se presentan los paradigmas de los tiempos compuestos de los modos indicativo y condicional y se comentan algunas particularidades de su estatus gramatical [véase, a este respecto Nagórko, 2005: 95-96; Saloni, 2007: 19-22], es verdad queel antiguo pluscuamperfecto de indicativo (p.ej., przeczytat byt, esp. [él] había leído), prácticamente, ha caído en desuso mientras que el empleo de la forma compuesta del modo condicional es poco frecuente:

(20) Bylbym zapomniat: jutro mamy zebranie.

La ausencia de los tiempos compuestos con el rasgo temporal 'anterioridad' condiciona el uso de adverbios temporales tales como wcześniej, przedtem (esp. antes), etc. 


\section{Observaciones finales}

1) Las diferencias cuantitativas y las oposiciones funcionales basadas en las marcas morfológicas y en los valores gramaticales que les corresponden,

2) la biaxialidad del sistema temporal del castellano frente a la monoaxialidad de los tiempos del polaco,

3) el desplazamiento temporal que en español, a diferencia del polaco, funciona como principio general en la organización del sistema de tiempos gramaticales,

4) la presencia del subsistema de los tiempos compuestos en castellano frente a la ausencia de estos últimos en polaco son los factores que determinan las diferencias básicas existentes entre los sistemas temporales de los idiomas en cuestión y condicionan tanto los llamados usos dislocados como las posibles matizaciones discursivas que se dan a través de la actualización textual de los tiempos gramaticales del castellano y del polaco.

\section{Bibliografía}

BELLO, A. (1847/1984), Gramática de la lengua castellana, EDAF, Madrid. CARTAGENA, N. (1999), "Los tiempos compuestos", en: Bosque, I., Demonte, V. (eds.), Gramática descriptiva de la lengua española, vol. II, RAE - Espasa Calpe, Madrid, pp. 2935-2975.

HERNÁNDEZ ALONSO, C. (1986), Gramática funcional del español, Gredos, Madrid.

NAGÓRKO, A. (2005), Zarys gramatyki polskiej, Wydawnictwo Naukowe PWN, Warszawa.

NOWIKOW, W. (2012a), “Lenguas 'artículo + tiempo' vs. lenguas 'caso + aspecto' (sobre las diferencias tipológicas entre el español y el polaco)", en: Dutka-Mańkowska, A., Kieliszczyk, A., Pilecka, E. (dir.), Grammaticis Unicis. Mélanges offerts à Bohdan Krzysztof Bogacki, Wydawnictwo Uniwersytetu Warszawskiego, Warszawa, pp. 237-244. 
NOWIKOW, W. (2012b), "Sobre el estatus gramatical de los cambios en el sistema de los pronombres personales de $3^{\mathrm{a}}$. persona con función de complementos directo e indirecto", en: Luquet, G. (éd.), Morphosyntaxe et sémantique espagnoles. Théories et applications, Presses Sorbonne Nouvelle, Paris, pp. 127-136.

NOWIKOW, W. (2013a), "Sobre la modalización del contenido proposicional: contraste tipológico entre lenguas románicas y eslavas", en: Pamies Bertrán, A. (ed.), De lingüistica, traducción y lexico-fraseología. Homenaje a Juan Dios Luque Durán, Editorial Comares, Granada, pp. 65-72. NOWIKOW, W. (2013b), "Ahora + Copretérito y el paralelismo vectorial entre cantaba ycanta (sobre un "presente en el pasado")", en prensa.

PÁTROVICS, P. (2000), "Aspektualität - Kasus - Referentialität - Temporalität. Ihre Relation im Deutschen und in den slawischen Sprachen”, en: Kątny, A. (Hrsg.), Aspektualität in germanischen und slawischen Sprachen, Wydawnictwo Naukowe UAM, Poznań, pp. 69-86.

PERLIN, J. (1996), "Opis kategorii czasu w systemach jednoseryjnych (na przykładzie polszczyzny)", Biuletyn Polskiego Towarzystwa Językoznawczego / Bulletin de la Société Polonaise de Linguistique, LII, pp. 107-112.

ROJO, G. (1974), "La temporalidad verbal en español”, Verba, 1, pp. 68-149. ROJO, G., VEIGA, A. (1999), "El tiempo verbal. Los tiempos simples", en: Bosque, I., Demonte V. (eds.), Gramática descriptiva de la lengua española, vol. II, RAE - Espasa Calpe, Madrid, pp. 2867-2934.

SALONI, Z. (2007), Czasownik polski, Wiedza Powszechna, Warszawa.

VEIGA, A. (1991), "Compound Tenses and Verbal System Structure. A Functional Approach from Modern Spanish", en: Feldbusch, E., Pogarell, R., Weiss, C. (Hrsg.), Neue Fragen der Linguistik, Max Niemeyer Verlag, Tübingen, pp. 243-251.

VEIGA, A. (2008), "Co-pretérito" e "irreal" / "imperfecto'e "inactual". El doble valor de cantaba en el sistema verbal español y algunos problemas conexos, Editorial Axac, Lugo. 